\title{
The Differentiation and Analysis about the Art Nationality Question
}

\author{
Lingjuan Wang \\ School of Architecture \\ North China University of Water Resource and Electric Power \\ Zhengzhou, China
}

\begin{abstract}
The western culture is overwhelmingly attractive to the economic backward nationalities. Presently the relationship between different nationalities become closer and closer, so it has realistic meaning to all the nationalities all over the world to learn correctly about the dialectical relationship between the nationality and cosmopolitan.
\end{abstract}

Keywords—nationality; cosmopolitan; blends; coexistence

\section{INTRODUCTION}

Overview the process of human civilization on historical and global viewpoint, Some of "the eternity objects" have been being inherited and sublimated, some of "the temporary concepts " has been being abandoned and corrected. This is also the problem for artistic reflection and recognition of China's modern art. In the field of art, the reflection and denial of Chinese culture become mainstreams since the modern times. The traditional painting art has also been savaged at the same time. The fight for "four Kings" by $\mathrm{Mr}$ Chen Duxiu, the idea of "Chinese painting in the modern time was declining" by Mr Kang Youwei, both of them pay attention to the introduction of western realism, but they all are suspended to hide the spirit of the Chinese traditional painting essence. At present, although their some radical understanding and behavior has been corrected, some phenomenon still exists, such as the wrong cognition and expression of the art contemporary. Under the influence of the theory of "Chinese and western combination, the concept and value of Chinese traditional painting virtually keep pace with the western standards. It has huge inestimable influence on the innovation and development of Chinese traditional painting; some modern artworks are the direct imitations of western art symbols. The professor $\mathrm{Mr}$ Gao Minglu of Pittsburgh University also believes that modernity in China is a kind of the dislocation of time and space. When the modernism in the western countries became cheap and mass, while it turn to be a kind of noble, fashionable, valuable pursuits in China.

In the 20th century, the whole China has experienced a industrial civilization modernization transformation from the agricultural and handcraft industry civilization covering aspects of political, economic, social and cultural. The Chinese traditional culture faces serious challenges inevitably in this huge social cultural reformation. The nationality of the artistic creation becomes the question to be continuous discussed continuously.

\section{The Discussion ABOUT CONNOTATION OF THE NATIONALITY}

On the cultural meaning, the nationality of art is the reflection of the cultural heritage for a long period, that is to say, to use our nation's unique artistic forms, artistic technique to reflect the real life. So the art works have strong our nationality characteristics and nationality style. (1) Mr Ji Xianlin says: "a nation create his own culture and develop it continuously to form the traditional culture, which is nationality; a nation created culture and accept other nationalities culture during the process of our own cultural development, which is the contemporary. The nationality and contemporary are in conflict but also unified. (2) The artworks of nationality characteristics are based on the national art tradition and aesthetic consciousness. The artworks give expression to the national people's life, thoughts and feelings, desires and art aesthetic interest, using the traditional art forms.

In present, the diversified times of the coexistence of the artistic forms and artistic techniques, the nationality of Chinese art has not only reflected by the national unique ink painting, but also create the artwork of "national style and national style" by imported from western paintings and other multimedia, video and other forms. Thus it can be seen that the nationality of art is originated from the traditional cultural heritage and meanwhile is divergent into different forms and techniques. And it is developed and perfected by the new exploration. We can walk out from the one kind of esthetic mode and give expression to our national culture by grasping more vivid spiritual connotation.

Under our times development, the meaning of nationality is also been corrected. It becomes an important element that the nationality can carry the art contemporary and supply the contemporary continuous motivation. The contemporary can extend the nationality's art connotation. The Chinese traditional painting has concrete and abstract two features. It has standards as vivid technique with meaningful expression. The technique "using shape to express the spirits" has developed the space for the concrete objects. The Chinese painting spirits give the correct expression to kind of views as "Nature and Man in the one". It is the unique values and 
humanistic spirits of Chinese culture. The spirits fully demonstrate the inner esthetic value of Chinese art.

Nowadays, it is a modern society with information. People's living and thinking mode has been changed with the changes of the living environments. If we still use the traditional emotion expression standard, our expression is the false expression. The nationality of the art manifests the civilized consciousness of Chinese culture. We need start from our historical tradition to treat the cultural development by peaceful mind and vision. We need to consider how to display the Chinese art's function and humanistic spirit to promote the mankind science progress. It is our tolerant artistic nationality for tolerating other art forms coexistence.

\section{The Present Situation of Chinese ART}

In the latter half period of last century, there different kinds of painting emerged for Chinese art. After 1950s 1960s and 1980s the western oil painting experienced different changes and gradually nationalized into Chinese national style. But it is only the simple superficial expression. Actually, from the beginning of the 20th century, the Chinese artists of 4th-5th generations have worked hard to give birth to a new Chinese oil painting expression of Chinese cultural spirits. During this period, there emerge several representatives of the Chinese oil paintings. The combination of western and Chinese paintings is very different from the previous unilateral cognition and the crazy cultural pursuits of "the great leap period". This cultural expression style itself is the process of destruction and recreation. It seems very important for studying the traditional culture. In 1990s, the new international style Chinese painting emerged to catering the international markets. It is called "Chinese oil painting impacted by US dollars". These paintings use the pure western culture as the unique standard. We call it's the short way to Chinese nationality. It could not exist for a long period and would fall into a very embarrassing circumstance. "To reach the world" is the desire and pursuits of most present artists. Nationality is the refection of the national spirits and culture. And the spirits and culture will be reflected by the different artworks under the changing of different eras.

We have 3000 years excellent national culture and art. It is our eternal treasure.

At the ancient times, people have the open, active and mobile romantic temperament; A the decade of Yin, its features are weird, funny and imaginative. Till the times of Zhou, people start to produce bronze ware. Different eras have different art features. Until Tang dynasty, Song dynasty and Ming dynasty and Qing dynasty, there appear kind of new art expression form as ink writing and painting style, which is very popular folk art.

The river, birds and beasts, wind and raining, water and fire, the entire natural phenomenon stimulate the Chinese people for creating the artworks. (4) It is kind of great freedom and revolution. People need to create more national artworks with their harmonious relationship of God and Person. The outward manifestation of the artworks reflects the national daily life and working life. The national emotion and culture is the concentrated reflection of nationality. The ink painting of Mr Lin Fengmian is adapted to the usage of the western lights and shadow. Mr. Wu Guanzhong put the Chinese painting style into his oil painting creation. And Mr. Zhao Wuji's paintings are full of the oriental and Chinese art spirits. All the artists above, they are famous internationally. The reason for their success is they give good expression of the national spirits and national characteristics. The art nationality is the reflection for their real feelings based on absorbing of the Chinese national culture. The nationality of the artworks is formed by the surroundings of the artists such as the natural environments, the social environments, the social rules and other aspects. In recent years, the succeed artists as Xubing and Cai Quoqiang they all stand on the international culture viewpoints of world innovation, using Chinese art symbols to express the theme of the times. They need learn from the western culture and art manifestation pattern and combine the advantage of the western culture with the Chinese national art. So no matter of the artists' style, they all need to think about the excavation of the Chinese national culture essence. We need to inherit our national culture and traditional culture; meanwhile, we also need to keep peace with the modernization and internationalization.

\section{The Blends of Chinese And Western Cultures}

It is not the self-seclusion to protect our own nationality. We cannot ignore the essence of other nationalities art; It does not means to clear up our own national characteristics by absorbing other nationalities art essence. We cannot achieve a kind of art to covering all the art forms advantages, we need to perfect and develop our own national arts by continuous absorbing from other nationalities art essence.

First of all, we cannot feel extremely arrogant about the protection of our own nationality of art; we need learn to tolerate other nationalities culture and arts. We have the brilliant nationality history but we cannot show off and take advantage of our seniority, we need to take it as our motivation for becoming much stronger and better. Each coin has two sides, when we show off our Chinese paintings have a supreme artistic conception and look down up on the western's low crafts technique. On the contrary, we are admitting our reckless and the western's precision. All over the world, each nationality has built his excellent arts, such as the famous and brilliant sculptures of Greek. We need to tolerate and learn from such excellent national arts. Such as our studies of Chinese ancient civilization is not the pure knowledge of Han nationality. Our present's Chinese culture is the combined results of our different nationalities. Throughout the history, Hua Xia nationality's formation comes from the combination of Yan tribe and Man tribe. In Chinese slave society, the combination of Xi Zhou and the surrounded minority give birth to our great culture of Han nationality. And till to Tang dynasty, the culture of western Buddhism is brought into our Han culture. To be assured that there also exist several powerful minorities along the Chinese history, but finally they are vanished from our history. The main reason is that they are arrogant and selfclosing to other nationalities culture and arts. 
Secondly, it does not mean to clear up our own national characteristics by absorbing other nationalities art essence. We need to learn how to blend the different nationalities culture and arts. The blend of Chinese and western cultures does not mean the simple imitation or copy. It means learning, absorbing and using into our own creation. Looking back to the Chinese modern times arts development, we have learnt and blended lots of essence from the western arts forms by cultural impacting with western nationalities. Learning and Blending does not mean to lose our own nationality. We are forming a kind of new national spirits and tradition. As remarks of Professor Mr. Bao Huashi of Michigan University, when European peoples started to substitute their classicism and realism of Chinese ancient painting of Tang and Song dynasty, the Chinese traditional intellectuals were keening on learning the western renaissance conservative tradition

\section{The Arts of Absorption, COEXISTEnCE AND ACCOMMODATION}

The nationality could not be equal to cosmopolitan and also they could be separated. Both are different but connected with each other. The global brilliant art is generated by different nations and different art forms of different styles. We cannot create a kind of arts to contain all the different arts forms and we also feel difficult to image a kind of arts to lose his nationality art characteristics. If there only has one kind of arts all over the world, we will lose the true meaning of arts appreciation. We need learn and absorb the arts essence from other nationalities. We need learn to choose our own national arts tradition and also learn to select the other nationalities arts. We call for making the choice in a creative way not in a imitative way. Such as the United States, there are lots of coexistence nationalities. Their different cultures could not conquer each other, so coexistence is the best choice. It is the reason why the USA native nationality becomes stronger and stronger.

Meanwhile, our nationality itself is various. The variety comes from our different personal life experience and emotional experience even the artists' unique absorption and reference of nationality arts factors. The arts nationality is another commonality to the artists' personal creation. The personality of the artist is the foundation. If there was no personality of the artist, there is no our nationality arts. We need to use a kind of generous attitude of the absorption, coexistence and accommodation to display our nationality creation talent and arts wisdom.

\section{REFERENCES}

[1] "Cihai", shanghai lexicographical book publishing house, 1979 (4132)

[2] Ji Xianlin "The communication between eastern and western culture, esternization", Guangming Daily, January, 6th,2005

[3] Wang Qingsheng "Paintings_ — The conflict between the eastern and western cultures", Beijing University Publishing House, 1991, (121)
[4] Wang Bi. "Lao-zi · Twenty Seven Year" (annotation) , Speech Integration of Lao-zi and his students (book 3) Lao-zi "tao te ching" (part one) [M], Zhong Hua Book Company 